\title{
TU/e EmonOWEN

\section{Initial operation of a newly developed multichord motional Stark effect diagnostic in KSTAR}

\section{Citation for published version (APA):}

Chung, J., Ko, J., Wi, H., Messmer, M. C. C., Schenkelaars, S., Scheffer, M., \& Jaspers, R. J. E. (2016). Initial operation of a newly developed multichord motional Stark effect diagnostic in KSTAR. Review of Scientific Instruments, 87(11), 1-4. [11E503]. https://doi.org/10.1063/1.4955483

\section{Document license: \\ TAVERNE}

DOI:

$10.1063 / 1.4955483$

Document status and date:

Published: 01/11/2016

\section{Document Version:}

Publisher's PDF, also known as Version of Record (includes final page, issue and volume numbers)

\section{Please check the document version of this publication:}

- A submitted manuscript is the version of the article upon submission and before peer-review. There can be important differences between the submitted version and the official published version of record. People interested in the research are advised to contact the author for the final version of the publication, or visit the $\mathrm{DOI}$ to the publisher's website.

- The final author version and the galley proof are versions of the publication after peer review.

- The final published version features the final layout of the paper including the volume, issue and page numbers.

Link to publication

\section{General rights}

Copyright and moral rights for the publications made accessible in the public portal are retained by the authors and/or other copyright owners and it is a condition of accessing publications that users recognise and abide by the legal requirements associated with these rights.

- Users may download and print one copy of any publication from the public portal for the purpose of private study or research.

- You may not further distribute the material or use it for any profit-making activity or commercial gain

- You may freely distribute the URL identifying the publication in the public portal.

If the publication is distributed under the terms of Article 25fa of the Dutch Copyright Act, indicated by the "Taverne" license above, please follow below link for the End User Agreement:

www.tue.nl/taverne

Take down policy

If you believe that this document breaches copyright please contact us at:

openaccess@tue.nl

providing details and we will investigate your claim. 
Initial operation of a newly developed multichord motional Stark effect diagnostic in KSTAR

J. Chung, J. Ko, H. Wi, M. Messmer, S. Schenkelaars, M. Scheffer, and R. J. E. Jaspers

Citation: Rev. Sci. Instrum. 87, $11 \mathrm{E} 503$ (2016); doi: 10.1063/1.4955483

View online: http://dx.doi.org/10.1063/1.4955483

View Table of Contents: http://aip.scitation.org/toc/rsi/87/11

Published by the American Institute of Physics

\section{Articles you may be interested in}

Instrumentation for a multichord motional Stark effect diagnostic in KSTARa)a)Contributed paper, published as part of the Proceedings of the 20th Topical Conference on High-Temperature Plasma Diagnostics, Atlanta, Georgia, USA, June 2014.

Rev. Sci. Instrum. 85, 11D82711D827 (2014); 10.1063/1.4891161

Sensitivity of magnetic field-line pitch angle measurements to sawtooth events in tokamaks Contributed paper, published as part of the Proceedings of the $21 \mathrm{st}$ Topical Conference on High-Temperature Plasma Diagnostics, Madison, Wisconsin, USA, June 2016.

Rev. Sci. Instrum. 87, 11E54111E541 (2016); 10.1063/1.4962058 


\title{
Initial operation of a newly developed multichord motional Stark effect diagnostic in KSTAR
}

\author{
J. Chung, ${ }^{1, a)}$ J. Ko, ${ }^{1}$ H. Wi, ${ }^{1}$ M. Messmer, ${ }^{2}$ S. Schenkelaars, ${ }^{2}$ M. Scheffer, ${ }^{2}$ \\ and R. J. E. Jaspers ${ }^{2}$ \\ ${ }^{1}$ National Fusion Research Institute, Yuseong, Daejeon 305-333, South Korea \\ ${ }^{2}$ Eindhoven University of Technology, 5612 AZ Eindhoven, The Netherlands
}

(Presented 8 June 2016; received 4 June 2016; accepted 19 June 2016; published online 13 July 2016)

\begin{abstract}
A photo-elastic modulator based 25-chord motional Stark effect (MSE) diagnostic has been successfully developed and commissioned in Korea Superconducting Tokamak Advanced Research. The diagnostic measures the radial magnetic pitch angle profile of the Stark splitting of a D-alpha line at $656.1 \mathrm{~nm}$ by the electric field associated with the neutral deuterium heating beam. A tangential view of the neutral beam provides a good spatial resolution of $1-3 \mathrm{~cm}$ for covering the major radius from $1.74 \mathrm{~m}$ to $2.28 \mathrm{~m}$, and the time resolution is achieved at $10 \mathrm{~ms}$. An in-vessel calibration before the vacuum closing as well as an in situ calibration during the tokamak operation was performed by means of specially designed polarized lighting sources. In this work, we present the final design of the installed MSE diagnostic and the first results of the commissioning. Published by AIP Publishing. [http://dx.doi.org/10.1063/1.4955483]
\end{abstract}

\section{INTRODUCTION}

Real-time control of the current profile is essential for the Korea Superconducting Tokamak Advanced Research (KSTAR) superconducting tokamak that is exploring a highbeta, long-pulse operation regime. The pulse duration of the $\mathrm{H}$-mode discharge in KSTAR has been extended longer than $40 \mathrm{~s}$ with a total auxiliary heating power up to $6 \mathrm{MW},{ }^{1}$ but the heating power is not big enough to observe a clear change on the current density profile in the range of operation. However the total heating power will be doubled in the next few years including electron cyclotron current drive (ECCD) sources, therefore measurements of the pitch angle profile will become more important in KSTAR. Moreover a real-time feedback control of a plasma shape played a key role in the extension of the pulse length, and this is applicable to the control of transport and magnetohydrodynamics phenomena. For example, feedback control of ELMs and NTMs is in preparation, and a real-time current profile control using a measured pitch angle became one of the important technical challenges of the KSTAR research program. The MSE diagnostic is used to measure the radial magnetic pitch angle profile in tokamaks, ${ }^{2}$ and a PEM based 25-chord system has been developed to support the profile control experiments in KSTAR. It has been two years since it had an engineering design. This was scheduled side by side with the construction of the first neutral heating beam system called NBI- 1 . The first commissioning of the MSE system was started a year after the full set of NBI-1 construction. A gap between the schedule is allowed so that

Note: Contributed paper, published as part of the Proceedings of the 21st Topical Conference on High-Temperature Plasma Diagnostics, Madison, Wisconsin, USA, June 2016.

a)Electronic mail: jinil@nfri.re.kr we could double check the nature of the beam spectrum in the tokamak.

\section{INSTALLATION OF THE OPTICAL SYSTEM}

Installation of the optical system has been done after the manufacturing of each optical and mechanical component based on the final engineering design as shown in Figure 1. Key elements of the optical system in the front optic are an optical fiber bundle, a dual photo-elastic modulator (PEM), and an optical housing that consists of a mirror, collection lenses, a beam splitter, a polarizer and a metal enclosure having a mounting socket of the fiber bundle. ${ }^{3}$ They were assembled as a single body before being installed in the beam diagnostic cassette of the tokamak. Since the optical alignment is highly concerned with a fabrication of the optical housing, it was very carefully performed in a high accuracy and clean environment. The optical housing was designed to have a position adjustable lens mount and a rotation knob of a linear polarizer allowing us to fine-tune the optical performance with a known polarized lightening source at a target distance in the laboratory. This was also a preliminary experience of the installation in the tokamak and the in-vessel calibration for a successful commissioning.

Figure 2 shows a layout of a single fiber channel and magnified surfaces of both termination ends. The whole 25 channels comprises of 475 fibers each $35 \mathrm{~m}$ long. Every 19 fibers are grouped vertically to the focal plane of the collection optics and circularly to the entrance focal surface of detection optics. The magnified photographs in the figure shows that optical terminations are fabricated with a good quality of a mechanical alignment and optical polishing. Fibers having a numerical aperture (NA) of 0.22 consist of a $600 \mu \mathrm{m}$ core and a $110 \mu \mathrm{m}$ cladding. All of the metal housing including the tiny fiber jacket is made of aluminum, which is non-magnetic, and black anodized except fiber polishing surfaces. 

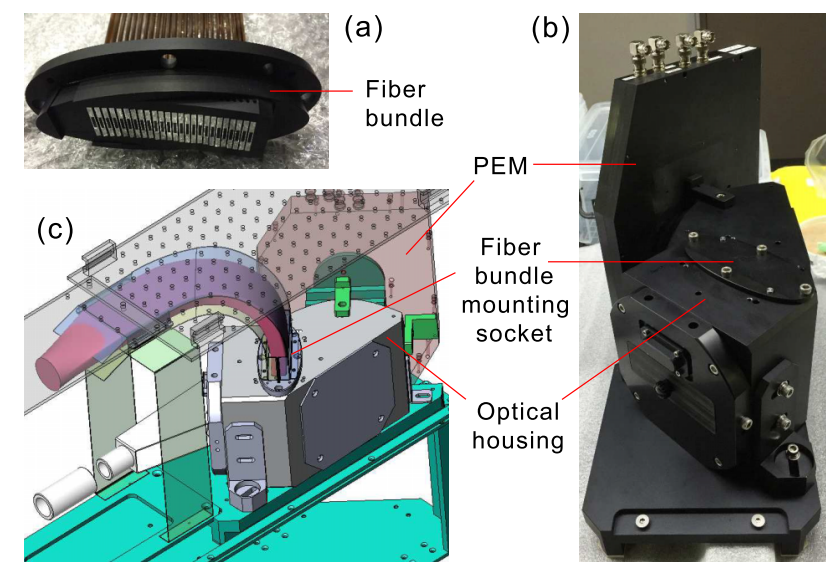

FIG. 1. Assembly of the front optic system. A fiber bundle (a) and an optical housing with a dual PEM (b) are assembled as one body. The front optic system has been installed in the beam diagnostic cassette as shown in the final engineering design (c).

\section{INSTALLATIONS IN THE DIAGNOSTIC AREA}

The MSE system is operated from the diagnostic room. PEM controllers, 25 channels of detection modules, and all the rest of sub-systems are sitting in this area where the other ends of the optical fiber bundles are installed. This area is accessible at all times and radiation shielded. As well as a new electrical ground for plasma diagnostics is available. Figure 3 shows a single channel of a detector and a whole detection system with 25 detection channels on the specially designed optical table. A detection module consists of a fiber mount, a pair of convex lenses, an interference filter, and an avalanche photodiode (APD) module. The fiber-mounting socket in the optical axis makes the polished fiber termination surface staying in a focal plane as a light source of the lens system, while the focal point is fit in a $3.0 \mathrm{~mm}$ in diameter APD chip. The gap between the lenses with a parallel light is required for the mounting of a narrow band-pass (FWHM $=0.42 \mathrm{~nm}$ ) interference filter on a motorized filter rotation stage. This tunable interference filter with the rotation stage that determines the center wavelength of the band-pass is controlled by an algorithm, which was designed to run in the background and automatically adjusts the center wavelength of the filter depending on the settings of the toroidal magnetic field and the NBI beam voltage. Here, the center wavelength shift as a function of temperature is not appropriate in KSTAR since the effective shot interval is less than $10 \mathrm{~min}$ and shot settings are changed often, while the temperature in the detection system is kept constant.

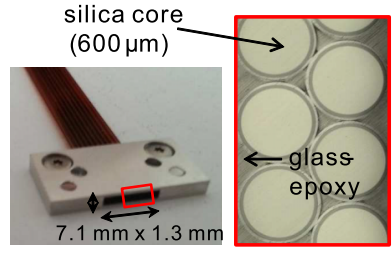

(a)

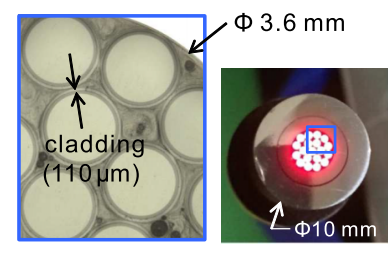

(b)
FIG. 2. Photographs of a single channel optical fiber bundle. 19 fiber cores are grouped vertically to the focal plane in the optical housing within the $7.1 \mathrm{~mm} \times 1.3 \mathrm{~mm}$ limit (a) and circularly to the detector end within the $3.6 \mathrm{~mm}$ in diameter limit (b). Twenty-five of this becomes the 25-channels MSE fiber bundle.

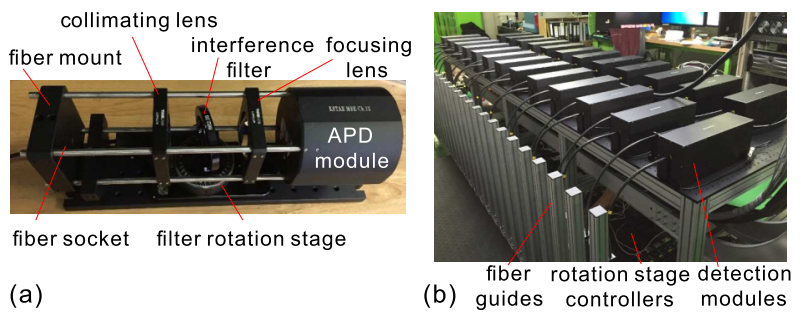

FIG. 3. Overview of the MSE detection system. Photographs show a detector module (a) and the full detection system consisting of 25 wired detection modules on the optical table (b).

Figure 4 shows a block diagram of the MSE control system. APD modules with $300 \mathrm{kHz}$ amplifiers and 32 data acquisition (DAQ) channels with a sampling rate of $2 \mathrm{MHz}$ are equipped. The DAQ channels record raw signals from the APDs and the reference signals from the PEM simultaneously at a 16-bit digital resolution to the KSTAR MDSplus database through the DAQ control server. Another 32 channels of second shadow digitizer that records the raw full rate data for a real-time digital signal processing (DSP) for an application with the plasma control system (PCS) is also prepared, but this is dealt with a long-term issue at this commissioning stage. The analysis server runs an analysis code based on a FFT algorithm as a post-shot off-line processing and uploads the results into the database. Here the analysis code demodulates the measured signals into harmonics of modulated frequencies and from that determines the Stokes vector (i.e., the polarization and amplitude characteristics) of the emitted light. Subsequently this is converted to the desired magnetic pitch angle. ${ }^{4}$ An in-vessel calibration before closing the vacuum vessel was the beginning of the initial operation. This is a procedure that the measured angle to be calibrated to an actual polarization angle with a known polarized calibration light source installed along the NBI beam propagation path. This also allowed us to confirm that all of the optical elements and electronics are all in the right position and healthy. The white light introduced through the detection module is focused right on the expected focal plane in the vessel, and the delivered light to the detector is focused in the boundary of the APD chip. The maximum noise signal level at the DAQ is $<5 \mathrm{mV}$, and no high frequency noises are measured in the grounding system. A tokamak clock signal with a frequency of $2 \mathrm{MHz}$ is used to operate the DAQ with the KSTAR shot sequence.

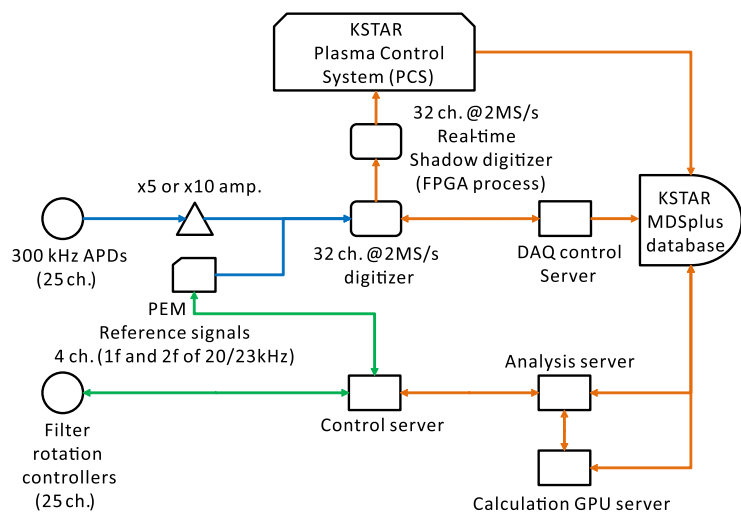

FIG. 4. Block diagram of the MSE control system. Flow of control signal is indicated in green, analog signal in blue and digital signal in orange. 

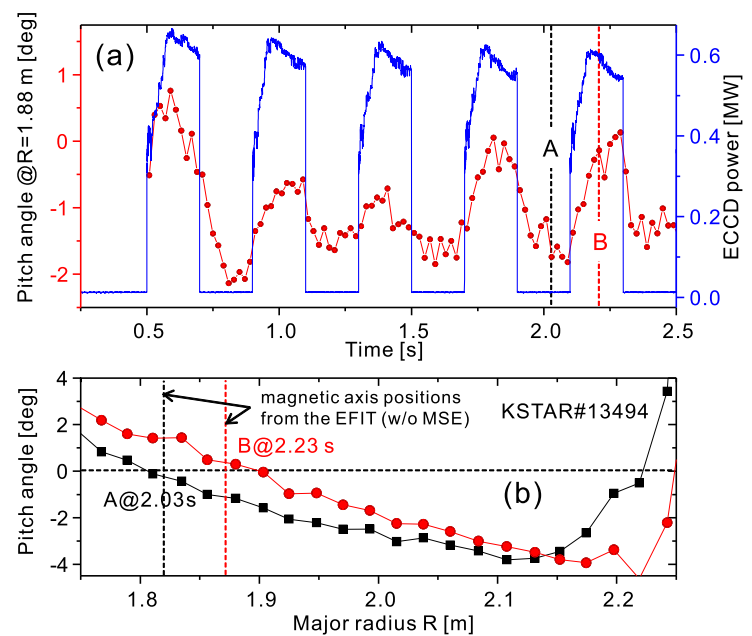

FIG. 5. ECCD modulation experiment of KSTAR shot 13494. A total of $0.6 \mathrm{MW}$ co-ECCD was switched on and off every $400 \mathrm{~ms}$. A measured pitch angle of a core channel during a ECCD modulation in time (a), and pitch angle profiles during ECCD on and off (b).

\section{INITIAL OPERATION RESULTS}

Optical components in the magnetic field influence the polarization direction by means of a Faraday rotation that needs to be corrected. Since the superconducting magnets cannot be operated before vacuum closing, the Faraday rotation cannot be taken into account during the in-vessel calibration. To overcome this, we have installed a position adjustable red light source and an in-vessel polarizer having a shutter to protect against coatings on the opposite diagnostic port from the MSE. The Faraday correction using the lightening was performed during charging the current of the toroidal superconducting magnet, and the measured Faraday offset is $0.8 \mathrm{deg} / \mathrm{T}$.

An example of initial tokamak pitch angle measurement is in Figure 5. The ECCD is an effective method to deliver highly localized current in the plasma, and the MSE is a unique tool for a direct measurement of the locally driven current. The measured pitch angle of a core channel follows the ECCD modulation clearly in time, and the measured profile at a different time slice also reacts to the current drive on and off. The zero-crossing of the profile shifted radially outwards, and this is consistent with positions of the magnetic axis from the enquilibrium fitting (EFIT) as indicated in Figure 3(b).
An additional important result needs to be emphasized here. The MSE collection optic system relaying part of the incoming light $(<600 \mathrm{~nm})$ using a dichroic beam splitter to the charge exchange recombination spectroscopy (CES) satisfies both diagnostics. Light intensity arriving at the CES detector is somewhat stronger than before, and the viewing area is more or less same. The CES is also successfully operated with the new optics in the last campaign.

\section{SUMMARY AND FUTURE PLAN}

A PEM based 25-chord MSE diagnostic has been developed and commissioned in KSTAR. We have successfully measured a time-resolved tokamak pitch angle profile with a spatial resolution of $1-3 \mathrm{~cm}$ and a time resolution of $10 \mathrm{~ms}$. Integration of the optical and electrical components in a tokamak environment including a computing and timing apparatus was a main concern during the first commissioning. Systematic errors are minimized and analysis algorithms are optimized. An additional amplifier between the APD module and the DAQ will be tested to increase the time resolution in the coming campaign. An application of a graphics processing unit (GPU) for a faster data analysis is also proposed. The use of an embedded digital lock-in algorithm in the shadow digitizer is a long-term study, and the analog lock-in technique is an alternative option for the real-time measurement. Equilibrium constraints for a q-profile and a current density profile using the measured pitch angle are in preparation by EFIT (Equilibrium Fitting) experts in KSTAR.

\section{ACKNOWLEDGMENTS}

This work was supported by the Korean Ministry of Science, ICT, and Future Planning under the KSTAR project contract.

${ }^{1}$ S. J. Wang, J. Kim, J. H. Jeong, H. J. Kim, M. Jeong, Y. S. Bae, and J. G. Kwak, AIP Conf. Proc. 1689, 030014 (2015).

${ }^{2}$ F. M. Levinton, R. J. Fonck, G. M. Gammel, R. Kaita, H. W. Kugel, E. T. Powell, and D. W. Roberts, Phys. Rev. Lett. 63, 2060 (1989).

${ }^{3}$ J. Chung, J. Ko, M. F. M. De Bock, and R. J. E. Jaspers, Rev. Sci. Instrum. 85, 11D827 (2014).

${ }^{4} \mathrm{R}$. Jaspers, M. Scheffer, and M. Messmer, Internal report under the research and development agreement between NFRI and TU/e, 2016. 